\title{
Chronic Kidney Disease (CKD) in Sri Lanka - Current Research Evidence Justification: A Review
}

\section{Sunethra Kanthi Gunatilake ${ }^{1 *}$, S. Sunil Samaratunga ${ }^{2}$ and Ruvini Takshala Rubasinghe ${ }^{1}$}

$1^{*}$ Department of Natural Resources, Sabaragamuwa University of Sri Lanka, Sri Lanka.sunethrasum@yahoo.com

${ }^{2}$ Department of Chemistry, University of Ilorin, Ilorin, Nigeria

\begin{abstract}
In this article, the current scientific evidence of Chronic Kidney disease with unknown aetiology $(\mathrm{CKDu})$, were critically reviewed and harnessed with other relevant literature with a view to justify the possible causative reason(s) for this chronic health problem. To this end, authors first reviewed the literature on socio-economic, environmental, meteorological, health and geo-environmental/chemical aspects in relation to the CKD of unknown aetiology in Sri Lanka and then studied the known aetiology of CKD (key medical facts) in detail highlighting a comprehensive list of causes. Based on the nature of economic development in the CKDu prevailing area, previous studies have suggested that the causative factor for CKDu is probably environmental and is related to the nature of anthropogenic activities. Therefore, authors investigated subject more into the chronic exposure to heavy metals associated with agricultural activities. Potential sources of heavy metals in the area are mentioned. The geochemical mobility and health effects of three selected elements namely arsenic (As), cadmium $(\mathrm{Cd})$ and Lead $(\mathrm{Pb})$ are studied in detail. The current scientific observations reported on CKD were evaluated with established chemical, geochemical, and health risk of $\mathrm{As}, \mathrm{Cd}$ and $\mathrm{Pb}$. According to the review, it can be justified that $\mathrm{CKDu}$ of the North Central Province (NCP) in Sri Lanka is a decease caused by the chronic exposure and cumulative effects of elevated levels of heavy metals associated with agricultural activities.
\end{abstract}

Keywords: Chronic Kidney Diseases (CKD); heavy metals; groundwater; fertilizer; agricultural activities

\section{Introduction}

The outbreak and prevalence of Chronic Kidney Disease with unknown aetiology $(\mathrm{CKDu})$ among people living in some areas confined to North Central Province (NCP), namely Dehiattakandiya, Girandurukotte, Kabithigollawa, Medawachchiya, Medirigiriya, Nikawewa and Padaviya in Sri Lanka (Figure 01) was first recognized and announced in early 1990's according to the 
hospital information and was later found to be endemic to such areas where agriculture is the main occupation and the main source of income of the people. The underline cause(s) of the CKDu have been yet unknown and is yet to be identified. The disease is proved to be endemic, therefore it is highly believed to be an environmentally induced disease.

Currently, the aetiology of $\mathrm{CKDu}$ is being under investigation by several research groups comprising scientists, biologists, geologists, chemists, medical experts, etc. There have been numerous continuous research studies ongoing focusing to elucidate the causative agent of $\mathrm{CKDu}$ since the outbreak of the disease. Several researchers have come up with hypothes gravitated on environmental factors for the probable cause of the disease. But the root of the disease is still in question and in search.

As such, there has been a rising incidence and prevalence of chronic kidney failures in NCP posing high burden to health sector in Sri Lanka due to the high cost involved and the poor outcome. Owing to the increase in number of patients as well as the disease related deaths exponentially, CKDu has currently become one of the most burning environment-related health issues of national concern in Sri Lanka. As the medical studies and other researches carried out so far have failed to establish a reliable aetiology, the Government of Sri Lanka has made a request to WHO headquarter in Geneva in 2008 to provide technical assistance in diagnosing the exact cause of the disease. In response to the request, WHO arranged a seminar with a panel of international experts, local researchers and stakeholders to initiate reviewing of available information to provide technical assistance in developing a research proposal for tracing and prevention of the disease. Under this research initiative, several research components have been proposed and initiated towards elucidating the aetiology of CKD.

Chronic Kidney disease is a subject that has been intensively studied globally by the scientists due to its mysterious nature. It has been recognized as a global population health issue. Reports reveal that there is 5-8\% in patient with renal replacement therapy (RRT) annually. It will be expected to increase renal disease (ESRD) patients to $70 \%$ by 2030 in developing countries due to economically-nonviable treatment methods (Carlos et al., 2009). The major chronic diseases that cause CKD are principally diabetes mellitus (DM) and Hypertension (HT) (USRDS, 2004). In addition, the number of environmental risk factors has been recognized globally as probable causes of CKD, namely exposure to heavy metals (arsenic, cadmium, lead, mercury, and chromium), agrochemicals, and nephrotoxic substances. Chronic arsenic exposure due to presence of arsenic in drinking water obtained from deep well (Tube wells) was reported as a cause for CKD in Bangladesh, Taiwan and India (Pritchard, 2007). Other risk factors are use of non-steroidal anti-inflammatory drugs (NSAIDs), eg. aspirin, and the infectious diseases like maleria, leptospirosis, 
hantavirus, and leprosy (endemic in Central America) (Soderland et al., 2010; Wedeen, and Qiant, 1991).

From studies conducted on Central America and Southern Mexico, high incidence and prevalence of CKD among male farmers $(<60 \mathrm{yrs})$ in coastal areas who are exposed to agrochemical is reported (Carlos et al., 2009; USRDS, 2004; Pritchard, 2007; Soderland et al., 2010) in the past decade. Nefrolempa study conducted in 2009 in Salvador, elevated prevalence of chronic kidney disease of unknown cause compared to other international reports has been reported (Carlos et al., 2009). Further, it was reported that CKD of unknown cause was associated with neither diabetes nor hypertension, but with age, male sex, hypertension and family history of chronic kidney disease, with loss of kidney function beginning at early ages. More vulnerable group to CKD was reported as male farmers with a dual burden of traditional (vascular) and non-traditional (occupational, toxic environmental) risk factors that could act in synergy (Carlos et al., 2009).

Most of the scientific studies done on CKD seemed to have taken so much of endeavors to justify diseases, symptoms and other related geo-environmental risk factors with the local environment where CKD prevailed in order to define a holistic approach as the possible preventive measures in an attempt to reduce burden and threat to the health of the people.

The purpose of this review paper is to postulate probable risk factor(s) based on the literature and on those of medical, clinical, toxicological and environmental information currently available on the CKD. The existing literature on the Chronic Kidney Disease (CKD) is found to be very interesting, informative and multi-disciplinary. However, it is realized that if the issue is localized and analyzed with local medical, clinical, toxicological, scientific, environmental, meteorological and socio-economic parameters, the most probable causative factor(s) is (are) likely to be established with a higher confidence level. Therefore current scientific evidences published on the CKDu in Sri Lanka were critically reviewed with that information established on medical, clinical, toxicological and scientific ground with an attention to local socio-economic, environmental, meteorological and health features. In this attempt, authors have come across with reliable articulated facts and health conditions related to CKD that can be utilized to justify the title of this paper and hereby wish to present those findings to provide insight of the causative factors that are giving rise to chronic diseases and conditions developing to the stages of CKD which are already been diagnosed by the medical experts in Sri Lanka.

\section{Current scientific evidence in CKDu in NCP in Sri Lanka}

NPC is the largest province in the country covering $16 \%$ of total country's land area, $10,723 \mathrm{~km}^{2}$. NCP consists of two districts called Anuradhapura and 
Polonnaruwa (Figure 01). Anuradhapura is the largest district with area 7,128 $\mathrm{km}^{2}$. There are 3742 villages. The province has a total population of $1,259,567$ in 2014 . More than $65 \%$ of the population belongs to farming population and to low socio-economic group.

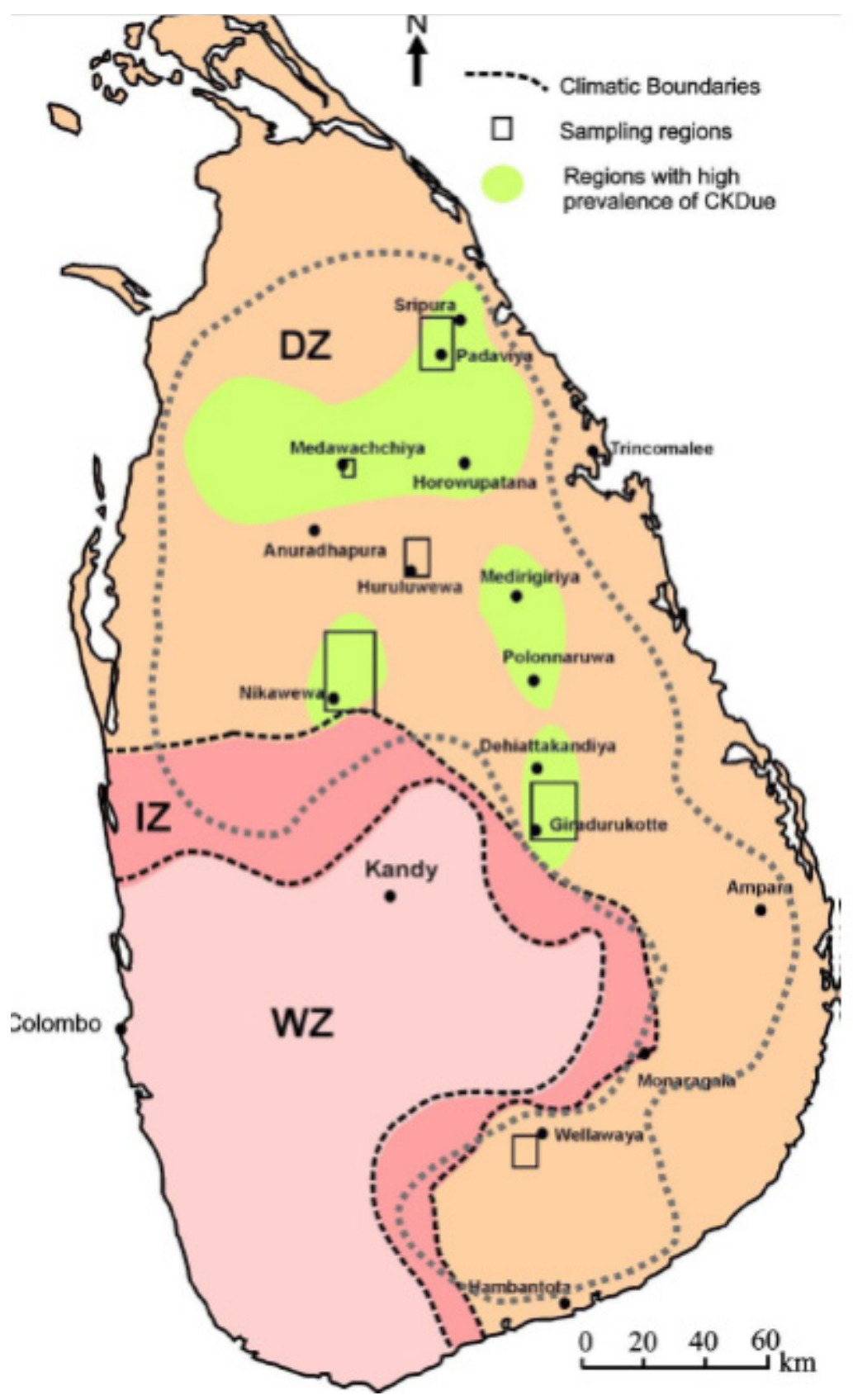

Figure 01: Regions of High Prevalence of CKDue in Sri Lanka 


\section{Socio-economic}

Sri Lanka's highly sophisticated ancient irrigation system networked storage reservoirs namely Tissawewa, Nuwarawewa, Basawakkulama, Kalawewa, Minneriya and Parakkrama Samudra with ingenious networks of feeder and distribution channels (many still in everyday use), which feed and regulate water levels located in NPC. This irrigation system transformed the dry-Zone plains of the NCP into a fertile land. In addition to that, those lakes serve the drinking water and recreational facilities for the people living around and drinking water and recreational facilities for large number of wild animals. People living away from lakes use dug wells and deep tube wells for extracting water for their daily consumption for last 20-25 years before that people in NPC sustained with reservoirs.

Agriculture is one of the key economic sectors in the area. Paddy production is the major agricultural activity and is cultivated under rain fed system including main irrigation schemes, medium and small tanks in Maha season (during North East monsoon period). Total rice production was 3,600,000 metric tons in 2011. Apart from rice, the other products that are cultivated during the whole year using seasonal tanks and underground water include sesame, millet, chilies, peanuts, fruit, vegetables and dairy produce. Combining ancient skills with modern progress, the NCP's many agricultural research stations and model farms assist farmers with contemporary know-how and technology. Livestock sector is an important component of the farming system of the affected areas which generates additional income, employment opportunities and highly nutritious food. Majority of people in the area depend on Poultry, Goat and Dairy farming while a small percentage of people depend on animals such as sheep, pig, turkey, gini fowl, duck and rabbit.

\section{Environmental}

Water Resources: Tanks, streams, and springs are the main sources of surface water in the NCP and are the main storage for rain water during the whole year. These are mainly used for the purpose of agricultural activities. Water for cultivation is also obtained from agricultural wells by lift irrigation. Ground water in the area is mainly use as a source of drinking water. In the past, several researchers have attempted to explain the etiology of CKDu. Herath et al., (2005) reported that high fluoride content in drinking water may be the cause of $\mathrm{CKDu}$, nevertheless, they have not been able to explain the reasons for absence of $\mathrm{CKDu}$ in places where drinking water contains extremely high content of fluoride. High content of fluoride in ground water, contamination of the water supply with artificial fertilizers used for paddy cultivation, use of aluminum utensils instead of clay pots for cooking and toxin released from blue green algae are some of the suspect reasons for these crises (Jayasumana et al., 2013). It has been reported that aluminium fluoride is a neurotoxic 
which cause Alzhiemier's disease (Foncin et al., 1986) and it is not observed among CKDu patients. Although the usage of low quality aluminium untensils was discouraged by the government in CKDu endemic areas, Also several research results revealed that water hardness vary among these areas from $60 \mathrm{mg} / \mathrm{L}$ to $820 \mathrm{mg} / \mathrm{L}$ (Fonseka et al., 2012; Jayasumana et al., 2013) and degree of hardness in groundwater resources of Sri Lanka appears to have a strong positive correlation with the distribution of prevalence of CKDu patients in Sri Lanka (Jayasumana et al., 2013; Fonseka et al., 2012). In 2010, it was reported that presence of toxins produced by cynobacteria in surface waters, particularly in the freshwater reservoirs was the reason for the disease, nevertheless results could not bring out a plausible explanation for prevalence of $\mathrm{CKDu}$ only among those who drink groundwater. As such, none of the previous work on the subject could adequately explain etiology of CKDu.

When available data scientifically analyzed it clearly identified that main culprit is the high ionicity of NCP ground waters in certain areas together with dehydration/insufficient intake of potable water under hot sunny stressful work conditions and routine alcohol consumption habits of the farming community in place of potable water during long working hours in the sun together with changes in weather patterns especially higher day time temperature with erratic precipitation due to climate changes. Aquifers of the NCP are constantly replenished by high ionicity waters from Mahaweli channels as well as frequent oxidation-reduction of those regolith aquifers releasing increasing quantities of ions to water table in the area making even dug well waters in certain areas not within safe ionicity for human consumption. In NCP has over 22000 man-made reservoirs including small tanks and water quality has remarkably changed with comparing the wet zone water. Due to more than 9 months retention time of water in these reservoirs with warm weather it makes good places for cyanobacterial growth, blooming and toxin production which are correlated with CKDu in NCP (Jayasekara et al., 2012). Therefore NCP areas are suffering from drinking water quality problems due to extensive agriculture, livestock practices, poor sanitary conditions and soil and climatic characteristics. As a result, the availability of suitable water sources for domestic consumption is scarce. The rate of water intake per unit area is high and excessive use of ground water has caused intrusion of saline water and high leaching rate of pollutants into the ground water aquifers. Hydrochemical data for groundwater in dry regions of Sri Lanka show that the higher levels of fluoride and hardness and low EC, iron, nitrate and phosphate levels with a slightly alkaline $\mathrm{pH}$ where the kidney patients are reported (Chandrajith et al., 2010; Athuruliya et al., 2003, Wanigasuriya et al., 2008; Athuraliya et al., 2006; Jayasekara et al., 2011; Perera et al., 2008). Movements of groundwater have a considerable effect on fluoride distribution and concentration controlled by rainfall and facture density of the basement rocks. 
It has been observed that all five regions affected with the CKDu encompass a well developed irrigation systems comprising of reservoirs. Water from these reservoirs is mainly used for agricultural purposes. However, the people who live in these areas consume water from shallow wells and water levels of these shallow wells are proportionate to the water levels of the canals indicating that the ground water table is recharged from irrigation canals and reservoirs. The presence of the affected villages located below the level of the reservoirs and canals indicate the possibility of irrigated water draining to the shallow wells of the households which is the source of drinking water.

\section{Meteorological}

The area has a climate with an annual average temperature and rainfall of $32^{\circ} \mathrm{C}$ and 1,450 $\mathrm{mm}$, respectively. The area falls into low country Dry Zone of Sri Lanka and the climate is characterized by high temperature and low rainfall. Majority of rainfall occurs during the North East monsoon (DecemberFebruary), and rest is experienced during the Second Inter Monsoon (October to November). A small amount of rain is received during South West monsoon (May to September). This area receives sufficient rainfall by cyclones and depressions in some years. Annual average temperature of the area ranges from $24-33^{\circ} \mathrm{C}$. Temperature is warm throughout the year and records highest from May to August. Relative humidity varies between $70-82 \%$ within the year.

\section{Health}

Disease wise the people are more vulnerable to Malaria and Japanese encephalitis (Meningitis) (Wanigasuriya et al., 2011). But CKDu is a new threat to this area. There was no such disease before 20-25 years. Some medical/clinical, epidemiological and geo environmental scientific findings on this new health threat, $\mathrm{CKDu}$, are compiled below for further analysis with established medical, clinical and research data worldwide on Chronic renal failures.

\section{Medical / Clinical Observations}

\section{a. Tubulo-intertitial Disease}

Based on the medical evidences obtained from previous medical examinations and tests (through kidney biopsy and patients consultations and treatments) so far, it has been revealed that the CKDu confined to NCP of Sri Lanka is a disease caused by chronic tubulo-interstitial diseases and has very slow progression to end-stage renal failure (Chandrajith et al., 2010). It was reported that the most of the cases of CKDu were associated neither with diabetes mellitus nor with hypertension. 


\section{a-1. Tubulo Proteinuria and Microalbuminuria}

The CKDu in Sri Lanka is not a disease caused by known chronic diseases such as diabetes mellitus and hypertension, the major diseases leading to CKD. Clinically, the CKD is characterized by proteinuria (Athuraliya et al., 2003) and microalbuminuria (Wanigasuriya et al., 2011).

Aturaliya et al., 2003 stated that from their population studies, $45.6 \%$ of the patients were found to be affected with early stage CKD with persistent proteinuria and $35 \%$ of patient with late stages CKD, based on Creatinine clearance (Cr.cl) data, $\mathrm{Cr} . \mathrm{cl}>60 \mathrm{ml} / \mathrm{min}$ and $\mathrm{Cr} . \mathrm{cl}<30 \mathrm{ml} / \mathrm{min}$, respectively. The main occupation of the people was rice farming. It was later reported that of the adult employed population, $5.6 \%$ of the farmers were proteinuric (Chandrajith et al., 2010).

Wanigasuriya et al., 2011 reported microalbumnuria detected for males and females associated with different risk factors related to CKDu. Those detected microalbuminuria values are Smoking $(p<0.001)$, alcohol use $(p=0.003)$, hypertension $(\mathrm{p}<0.001)$, diabetes $(\mathrm{p}<0.001)$, urinary tract infection (UTI) $(p=0.034)$ and consumption of water from wells in the fields $(p=0.025)$. Based on these data, they have concluded that patients were associated with microalbuminuria. In the binary logistic regression analysis, hypertension, diabetes mellitus, UTI, drinking well water in the fields, smoking and pesticide spraying were found to be significant predictors of microalbuminuria (Wanigasuriya et al., 2011). In their previous study (Case -control study) carried out in 2008 on same risk factors for $\mathrm{CKDu}$, they have reported, being a farmer $(\mathrm{p}<0.001)$, using pesticides $(\mathrm{p}<0.001)$, drinking well water $(\mathrm{p}<0.001)$, having a family history of renal dysfunction $(\mathrm{p}=0.001)$, use of ayurvedic treatment $(\mathrm{p}<0.001)$ and a history of snake bite $(\mathrm{p}<0.001)$ (Wanigasuriya et al., 2008).

\section{a-2. Other Symptoms (Bone disease, Anaemia and Paraesthesia)}

Some other clinical assessments of patients at endemic areas have revealed some dermal pigmentations such as hyper pigmentation and karatosis observed in palms and soles by the research team at University of Kelaniya, Sri Lanka. Other symptoms that have been observed during clinical assessment are body weakness (Bone disease), headache, anemia, nausea, burning of eyes, epigastric pains and paresthesia.

Chandrajith et al., 2010 have mentioned that anemia is reported mild at early stages of CKD with increased severity at the later stages. Hypertension can be observed at the later stage. Edema is the late feature of the disease. Other common renal impairments reported are perivascular, periglomerular and focal interstitial hypocellular fibrosis, tubular atrophy and glomerular sclerosis. It was also reported that Ultasonographic imaging showed increased echogenicity, and loss of corticomedullary demarcation in late stages. 
Based on the above clinical evidences, it can be concluded that the CKDu is a disease more associated with tubulo-interstitial diseases that are commonly observed in toxic nephrophathies and less associated with glomerular deceases.

\section{b. Epidemiological Observations}

High incidence and prevalence of CKD of uncertain etiology (CKDue) observed in the certain geographical areas of the north central province of Sri Lanka, namely in Medawachchiya, Girandurukotte, Kabithigollawa, Padaviya, Medirigiriya, Dehiattakandiya and Nikawewa areas. This total area covers approximately $10,723 \mathrm{~km}^{2}$ with a population of about 2.5 million out of which more than $95 \%$ live in rural areas. Towards elucidating the aetiology of $\mathrm{CKDu}$, several research teams are conducting population screening, analysis of geoenvironmental factors, genetic studies and cohort studies.

The geographical distribution of CKDu is discussed in the Chandrajith et al., 2010. They have carried out a population screening using multistage sampling technique and reported that the point prevalence of CKDu is about 2-3\% among the subjects above 18 years. Population studies done by Athuraliya et al., 2006 have also shown that the prevalence of CKDu in above mentioned geographical areas in NCP, ranges from $2-3 \%$ of the population of the area. It was also reported that more than 9,000 patients are presently followed up at the regional hospitals of the high-prevalent areas. At present, over 5,000 patients are under treatment for renal failure (Athuraliya et al., 2006). Furthermore, about 2,000 patients are with the end stages of the disease each year with $100 \%$ mortality unless a kidney is transplanted.

It was also indicated from population screening that a young cohort of the population is affected with the disease. High incidence was reported in Medawachchiya. The prevalence of CKD among the adult ( $>18$ years) population was $5 \%(\mathrm{n}=2,600)$ and $3.7 \%(\mathrm{n}=4,107)$ from the overall population. The female-to-male ratio was $1: 1.3$. However, the disease is also observed in other areas of the affected regions. According to Jayasekara, et al., 2011, the epidemiology of the disease shows distribution of patients around the water reservoirs used for irrigation purpose and most of them are farmers.

The main sources of portable water in affected regions are shallow and deep wells. For instance, nearly $87 \%$ of the population in the areas most affected by CKDue use either dug well or tube well water (Perera et al., 2008). Water is consumed directly without any treatment except boiling in most cases. WHO report says that the disease is frequently starting at younger age group and commonly manifests in male farmers, typically between the age of 40-60 yrs engaged in the agriculture, low socio-economic class. The most affected patients belong to the $30-60$ year age group. 


\section{Chronic Kidney Disease (CKD) and the Known Aetiology}

Chronic Kidney Disease (CKD), a common public health problem worldwide, is also known as Chronic Kidney Failure (CKF), Chronic Renal Failure (CRF), or Chronic Renal Disease(CRD). CKD is also defined as either kidney structural damage or a decrease in Glomerular Filtration Rate (GFR) $<60 \mathrm{ml} /$ $\mathrm{min} / 1.73 \mathrm{~m} 2$ for three or more months. The common meaning of the above terms is slow progressive loss of kidney functions over time due to progressive destruction of renal mass. The main functions of the kidneys are to (www. emedicine.com):

- Filter out waste products and excess water from the bloodstream, to be passed out in the urine.

- Help regulate blood pressure

- Produce erythropoietin (epo) hormones which are needed to prevent anaemia.

- Help balance various salts and chemicals in the bloodstream at the right level.

Because of this slow progressive loss of kidney function, CKD often goes undetected and undiagnosed until it gets worse slowly over time. CKD is divided into five stages of increasing severity based on the progressive decline in GFR as follows.

- Stage 1: Kidney damage with normal or increased GFR $(>90 \mathrm{~mL} / \mathrm{min}$ $\left./ 1.73 \mathrm{~m}^{2}\right)$

- Stage 2: Mild reduction in GFR $\left(60-89 \mathrm{~mL} / \mathrm{min} / 1.73 \mathrm{~m}^{2}\right)$

- Stage 3: Moderate reduction in GFR $\left(30-59 \mathrm{~mL} / \mathrm{min} / 1.73 \mathrm{~m}^{2}\right)$

- Stage 4: Severe reduction in GFR $\left(15-29 \mathrm{~mL} / \mathrm{min} / 1.73 \mathrm{~m}^{2}\right)$

- Stage 5: Kidney failure (GFR $<15 \mathrm{~mL} / \mathrm{min} / 1.73 \mathrm{~m}^{2}$ or dialysis)

Patients with CKD stages 1-3 are generally asymptomatic. They get to realize that they have CKD only when their kidney function is down to $25 \%$ of normal. But symptoms appear when kidney function is less than one-tenth of normal. Whatever the underlying aetiology, the destruction of renal mass leads to a progressive decline in GFR (www.emedicine.com ). Approximately 1 million nephrons are present in each kidney, each contributing to the total GFR. In the face of renal injury (regardless of the aetiology), the kidney has an innate ability to maintain GFR, despite progressive destruction of nephrons, by hyperfiltration and compensatory hypertrophy of the remaining healthy nephrons. This nephron adaptability allows for continued normal clearance of plasma solutes. Plasma levels of substances such as urea and creatinine 
start to show significant increases only after total GFR has decreased to $50 \%$, when the renal reserve has been exhausted. The plasma creatinine value will approximately double with a $50 \%$ reduction in GFR. A rise in plasma creatinine from a baseline value of $0.6 \mathrm{mg} / \mathrm{dL}$ to $1.2 \mathrm{mg} / \mathrm{dL}$ in a patient, although still within the reference range, actually represents a loss of $50 \%$ of functioning nephron mass (www.emedicine.com ).

The Known Aetiology of Chronic Kidney Disease (CKD) (www.emedicine. com)

This is the section authors have found the key medical fact/evidence to articulate this review paper with reliable justification of current scientific evidences around the topic of this article. In this regard, the known etiology of CKD will be discussed in detail and will give a comprehensive list of causes. In the majority of cases progressive kidney damage is the result of a chronic disease (a long-term disease). These diseases can lead to cause permanent kidney damage or affect the function of kidneys giving rise to CKD. Common chronic diseases leading to chronic kidney disease include the following:

- Diabetic mellitus

- Hypertension

- Vascular diseases

- Glomerular diseases (primary or secondary)

- Tubulointerstitial diseases

- Urinary tract obstruction

According to Jayasekara et al., 2011, there has been high prevalence of chronic kidney disease in Sri Lanka due to tubulo-interstitial diseases that are commonly observed in toxic nephrophathies. Literature review also revealed that that exposure to heavy metals leads to cause tubulo-interstitial diseases. This is very strong scientific evidence found in the investigations conducted since the outbreak of CKD in mid 1990s in Sri Lanka. Exposure to heavy metals by the peoples in endemic areas of NCP is justified below using current scientific evidences.

Causes of tubulo-interstitial disease are:

- Heavy metals

- Chronic hypokalemia

- Chronic hypercalcemia

- $\quad$ Drugs (eg, sulfa, allopurinol)

- Infection (viral, bacterial, parasitic)

- Radiation nephritis

- $\quad$ Polycystic kidneys 
- Cystinosis

- $\quad$ Sjögren syndrome

- $\quad$ Sarcoidosis

- $\quad$ Multiple myeloma cast nephropathy

Factors other than the above diseases that may cause progressive kidney failure include the following:

- Systemic hypertension

- Acute insults from nephrotoxins or decreased perfusion

- Proteinuria

- Increased renal ammoniagenesis with interstitial injury

- Hyperlipidemia

- Hyperphosphatemia with calcium phosphate deposition

- Decreased levels of nitrous oxide

- Smoking

- Uncontrolled diabetes

- Kidney artery stenosis (the renal artery narrows or is blocked before it enters the kidney).

- Certain toxins - including fuels, solvents (such as carbon tetrachloride), and lead (and lead-based paint, pipes, and soldering materials).

- Fetal developmental problem

- Systemic lupus erythematosis - an autoimmune disease.

- Malaria and yellow fever

- Some medications, NSAIDs(non-steroidal anti-inflammatory drugs), such aspirin or ibuprofen.

- Illegal drug abuse - such as heroin or cocaine.

- Injury - a sharp blow or physical injury to the kidney(s)

Potential Sources of Heavy Metals in the Environment in NCP in Sri Lanka

The toxic nature of heavy metals makes it necessary to have knowledge of their source and fate in the environment. They are introduced into the environment by both natural and anthropological means. The anthropogenic sources most likely originate heavy Metals in NCP in Sri Lanka are mainly fertilizers, agrochemical, and animal manure largely used in agricultural purposes. Other sources that may contribute to heavy metal levels in the environment are leaded gasoline, lead based paints, and compost. Bandara et al., (2008) reported that presence of high concentrations of cadmium in drinking water and food as a potential cause of CKDu. It is most unlikely therefore that fluoride and cadmium are the sole causative agents of $\mathrm{CKDu}$. 
Early studies have shown acute or sub acute arsenic poisoning can cause tubulointerstitial nephritis (Prasad et al., 1995). Jayasumana et al., (2011) tested agrochemicals and confirmed the presence of arsenic in agrochemicals. Since no reported work is available as to the presence of arsenic in the bedrocks below Sri Lankan land mass, Jayasumana et al., (2013) reported that pesticides and fertilizers that are excessively used in paddy farming attributed as the most likely sources of arsenic in CKDu patients in the study area. Majority of people in north central, north western and eastern Sri Lanka are paddy farmers and they are heavily exposed to pesticides and fertilizers (Jayasumana et al., 2012).

\subsection{Natural Sources}

It is a well known fact that heavy metals in soil occur naturally due to weathering of parent materials by lithogenetic or pedogenetic processes at levels regarded as trace $(<1000 \mathrm{mg} / \mathrm{Kg})$ which is rarely toxic (Kabata-Pendias, and H. Pendias, 2001; Pierzynski, 2000).

\subsection{Anthropological Sources}

Agricultural \& Livestock runoff: use of land for agriculture and the practices followed by cultivation greatly affect the quality of surface and ground water. Intensive cultivation of crop with the application of fertilizers, pesticides and other chemicals results in the leaching of trace metals, inorganic and organic pollutants into water bodies.

\subsection{Other Activities}

In NPC, people are used to wash their dirty and dusty vehicles from the lakes. Large number of vehicle is washed into lakes daily. This also bring considerable amount of contaminants including heavy metals deposited on the dust,especially lead $(\mathrm{Pb})$ particulates, into lake water. In addition, environmental samples like water, soil and sediments in NCP may become contaminated by the accumulation of heavy metals through emissions from the land application of fertilizers, agrochemicals, animal manures and atmospheric deposition.

Soils may accumulate heavy metals from anthropological sources at levels high enough to cause risks to human health, animals, plants, and ecosystems (Amore et al., 2005). The heavy metals essentially become contaminants in the soil as their chemical forms (species) may render it more bioavailable (Amore et al., 2005). It is worth to mentioned here that heavy metals coming from anthropogenic sources tend to be more mobile, hence bio-available than lithogenic or pedogenic ones (Kuo et al., 1983; Kaasalainen and Yli-Halla, 2003). 
In NCP in Sri Lanka, agriculture is the main occupation and major source of income of the people. The area is characterized by intensive agricultural and livestock farming system. The most common cultivations are paddy, maize and vegetables. It is a known scientific fact that plants require macronutrients such as N, P, K, S, Ca and $\mathrm{Mg}$ and micronutrients such as $\mathrm{Co}, \mathrm{Cu}, \mathrm{Fe}, \mathrm{Mn}, \mathrm{Mo}$, $\mathrm{Ni}$, and $\mathrm{Zn}$, as well to grow and complete the lifecycle. All crops are supplied with these by means of fertilizer, soil conditioners and some plants sprays.

Farmers in NCP generally belong to low income group and are not bothered or concerned about environmental benefits or hazards. They are primarily interested and concerned in maximizing their crop yields and profits at the end. Therefore, large quantities of fertilizers and agrochemicals are regularly added to soils and plants to supply macronutrients N, P, and K for crop growth.

The compounds used to supply these nutrients in fertilizer and agrochemicals contain trace amount of toxic heavy metal such as $\mathrm{As}, \mathrm{Cd}$, and $\mathrm{Pb}$ as impurities. After long-term land application of fertilizer and agrochemicals, the content of impurities significantly increase in the soil and the water (surface and ground water) because those metals have no known physiological activity (Jones and Jarvis; 1981). Application of certain phosphate fertilizer inadvertently adds $\mathrm{Cd}$ and $\mathrm{Pb}$ including other potentially toxic elements (Raven et al., 1998).

Chandrajith et al., 2009 has reported trace elements contents (Table 01) in different fertilizers applied to paddy soils in different areas in NCP in Sri Lanka, in their attempt to find the causative agent of CKD. Those data reveals that considerable amount of $\mathrm{Cd}$ and $\mathrm{Pb}$ accumulates in agricultural soil in NCP due to application of fertilizer in the long run.

In addition, several common pesticides used extensively in agriculture contained substantial amounts of toxic metals, $\mathrm{Cd}, \mathrm{Pb}, \mathrm{As}, \mathrm{Cu}, \mathrm{Hg}, \mathrm{Mn}$, or $\mathrm{Zn}$. Compared with fertilizers, the amount of pesticides used restricted to particular sites or crops (McLaughlin et al., 2000) or type of the disease, but can contribute to slightly increase the total heavy metal concentration in the long run. 
Table 01: Content of trace elements $(\mathrm{mg} / \mathrm{kg})$ in different fertilizers collected from study regions (Chandrajith, 2009)

\begin{tabular}{|l|c|r|r|r|r|r|r|}
\hline Collected location & Fertilizer type & \multicolumn{1}{c|}{$\mathrm{Al}$} & \multicolumn{1}{c|}{$\mathrm{Cr}$} & \multicolumn{1}{c|}{$\mathrm{Ni}$} & $\mathrm{Cd}$ & \multicolumn{1}{c|}{$\mathrm{Pb}$} & \multicolumn{1}{c|}{$\mathrm{U}$} \\
\hline Anuradhapura & Urea & 37 & 3.9 & 1.4 & 0.4 & 3.8 & 6.0 \\
& $\mathrm{NPK}$ & 203 & 3.9 & 1.4 & 0.4 & 3.8 & 20.1 \\
& $\mathrm{TSP}$ & 9.949 & 52.9 & 35.2 & 3.6 & 50.7 & 107 \\
Medawachchiya & $\mathrm{Urea}$ & 32 & 3.9 & 1.4 & 0.4 & 3.8 & 6.0 \\
& $\mathrm{NPK}$ & 262 & 3.9 & 1.4 & 0.4 & 3.7 & 6.5 \\
& $\mathrm{TSP}$ & 9.405 & 43.6 & 27.1 & 4.0 & 79.2 & 75.9 \\
Medirigiriya & Urea & 25 & 210.3 & 1.4 & 0.4 & 3.7 & 28.3 \\
& $\mathrm{NPK}$ & 135 & 23.7 & 1.4 & 0.4 & 3.8 & 6.1 \\
& $\mathrm{TSP}$ & 8.563 & 59.5 & 22.3 & 46.1 & 41.1 & 5.8 \\
Girandurukotte & Urea & 54 & 19.6 & 1.4 & 0.4 & 6.0 & 25.3 \\
& $\mathrm{NPK}$ & 143 & 22.8 & 1.4 & 0.4 & 3.8 & 6.1 \\
& $\mathrm{TSP}$ & 9.016 & 65.9 & 24.2 & 39.8 & 58.2 & 64.1 \\
Girandurukotte & Urea & 27 & $\mathrm{Nd}$ & 1.6 & $\mathrm{Nd}$ & 4.0 & $\mathrm{Nd}$ \\
& $\mathrm{NPK}$ & 77 & 2.6 & 1.3 & 0.5 & 2.6 & 119 \\
& $\mathrm{TSP}$ & 5.177 & 19.2 & 10.6 & 2.3 & 67.2 & 364 \\
& Urea & 52 & 21.0 & 1.4 & 0.4 & 3.9 & 24.4 \\
& $\mathrm{NPK}$ & 140 & 22.1 & 1.4 & 0.6 & 3.8 & 6.1 \\
& $\mathrm{TSP}$ & 10,113 & 62.1 & 27.3 & 4.3 & 80.2 & 166 \\
\hline
\end{tabular}

$\mathrm{Nd}$ - not detected

Besides, the application of animal manures and composts to land also leads to accumulate heavy metals such as $\mathrm{Cd}, \mathrm{Pb}, \mathrm{As}, \mathrm{Cr}, \mathrm{Cu}, \mathrm{Zn}, \mathrm{Hg}, \mathrm{Ni}, \mathrm{Mo}, \mathrm{Se}$, $\mathrm{Tl}$, Sb, and so forth, in the soil (Basta et al., 2005). Certain animal wastes such as cattle, poultry and pig manures are commonly applied to top soil as soil conditioner either as solids or slurries (Sumner, 2000). Although those are seen as valuable fertilizers by farmers, those manures have the potential to cause metal contamination of the soil (Sumner, 2000; Chaney and Oliver, 1996). The livestock manures contain high concentrations of $\mathrm{Cu}$, and $\mathrm{Zn}$ and repeat application can cause considerable increase of these metals in the soil and water.

Soils act as the major sink for heavy metals and unlike organic contaminants, most metals do not undergo microbial or chemical degradation, and they remain in soil for a long time (Kirpichtchikova et al., 2006). They may undergo changes in their chemical forms (speciation) and bioavailability. Toxic metals in soil can inhibit the biodegradation of organic contaminants (Adriano, 2003; Maslin, and Maier, 2000). Also heavy metals may pose risks and hazards to humans and the ecosystem.

Geochemical Mobility and Health Effects of Arsenic(As), Cadmium (Cd), and Lead $(\mathrm{Pb})$ 
The most common heavy metals likely to be associated with CKDu in Sri Lanka are $\mathrm{Cd}, \mathrm{Pb}, \mathrm{As}$ and therefore discuss in terms of their chemical and environmental behaviors (Prasad, 1995; Bandara, 2008; Jayasumana et al., 2011). Those metals are important since they are capable of damaging the environmental, human and aquatic life due to the risk of bioaccumulation and biomagnification in the food chain, and the risk of surface and groundwater contamination.

Knowledge of the basic geo-environmental mobility of these heavy metals is necessary in understanding their speciation, bioavailability, associated health effects and remedial options. The fate of heavy metals in environmental samples depends largely on their chemical form and speciation. The speciation of heavy metals depends on the $\mathrm{pH}$ and their concentrations in environmental samples. Absorbed heavy metals are transformed into different chemical forms with varying bioavailability, mobility, and toxicity (Shiowatana et al., 2001) depending on the variation of such conditions.

\subsection{Geochemical Mobility of Arsenic (As), Cadmium (Cd) and Lead (Pb)}

Arsenic (As): Arsenic is a metalloid belongs to group VA and period 4 of the periodic table. It exhibits fairly complex chemistry and can be present in several oxidation states (-III, 0, III, V) (Smith et al., 1995). It occurs in a wide variety of minerals, mainly as $\mathrm{As}_{2} \mathrm{O}_{3}$, and recovers from processing of ores containing mostly $\mathrm{Pb}, \mathrm{Cu}, \mathrm{Zn}, \mathrm{Ag}$ and $\mathrm{Au}$. In aerobic environments, $\mathrm{As}$ (V) is dominant, in the form of arsenate $\left(\mathrm{AsO}_{4}{ }^{3-}\right)$ at various protonated forms, such as $\mathrm{H}_{3} \mathrm{AsO}_{4}, \mathrm{H}_{2} \mathrm{AsO}_{4}{ }^{-}, \mathrm{HAsO}_{4}{ }^{2-}$, and $\mathrm{AsO}_{4}{ }^{3-}$. Arsenate and other anionic forms of As behave as chelates and precipitate when metal cations are present (Bodek et al., 1988).

\subsubsection{Geoenvironmental mobility of Arsenic}

Many Arsenic (As) compounds adsorb strongly to soils. Hence, they are transported only over short distances in groundwater and surface water. Arsenic is associated with skin damage, increased risk of cancer, and problems with circulatory system (Scragg, 2006).

Cadmium(Cd): Cadmium $(\mathrm{Cd})$ is a transition metal positioned in the Group II B. It is a soft bluish-white metal chemically similar to the two other metals in group II B, Zn and $\mathrm{Hg}$. Cadmium shows chemical similarity to that of $\mathrm{Zn}$, which is an essential micronutrient for plants and animals. But $\mathrm{Cd}$ is a toxic metal and $\mathrm{Zn}$ substitution by $\mathrm{Cd}$ cause malfunctioning of metabolic process (Campbell, 2006). $\mathrm{Cd}$ is one of the four heavy metal poisons ( $\mathrm{Cd}, \mathrm{Pb}, \mathrm{As}$ and $\mathrm{Hg}$ ) and is not known for any essential biological function. 


\subsubsection{Geochemical mobility of Cadmium (Cd)}

Cadmium occurs as a major component in most zinc ores and therefore is a byproduct of zinc production. Cadmium is produced as an inevitable byproduct of $\mathrm{Zn}$ and occasionally lead refining. Its average concentration in the earth's crust is between $0.1-0.5 \mathrm{ppm}$. Cadmium traces naturally occur in phosphate, and have been shown to get into food through fertilizer application. Cadmium present as an impurity in phosphate fertilizers, detergents and refined petroleum products (Chandrajith et al., 2010).

Cadmium shows increased geochemical mobility under acidic environmental conditions. The land application of fertilizers and pesticides, increases the total concentration level of $\mathrm{Cd}$ in agricultural soils. Acidification of soils and surface waters increase the geochemical mobility of $\mathrm{Cd}$. As a result, $\mathrm{Cd}$ concentration in surface-water tends to increase as lake water $\mathrm{pH}$ decreases (Campbell, 2006). Possible exposure to $\mathrm{Cd}$ through food chain has been studied sine 1970s, for example, through the human consumption of shellfish or vegetables. More research have been carried out to research on the possible consequences by applying Cd-rich phosphate fertilizer and animal manure in soils on the crops meant for human consumption (Campbell, 2006). These researches have eventually led to stipulate highest permissible concentrations for human consumption (McLaughlin et al., 2000). The bioavailability of Cd is a measure to determine to what degree plant uptake cadmium (Weggler et al., 2004).

Lead $(\mathrm{Pb})$ : Lead is an element belonging to Group IV, Period 6 of the periodic table. Unlike Carbon (C) and Silicon (Si) in Group IV, it does not bind with another identical atom, and shows marked decrease in covalency and exists mainly in +2 oxidation state. Lead is a soft, malleable poor metal. It is also counted as one of the heavy metals. Lead(II) compounds are predominantly ionic (e.g., $\mathrm{Pb}^{2+} \mathrm{SO}_{4}{ }^{2-}$ ). Lead (IV) compounds tend to be covalent (e.g., tetraethyl lead, $\left.\mathrm{Pb}\left(\mathrm{C}_{2} \mathrm{H}_{5}\right)_{4}\right)$. Some Lead (IV) compounds, eg. $\mathrm{PbO}_{2}$, are strong oxidants.

The general forms of lead $(\mathrm{Pb})$ that are released into the soil, surface and ground waters are ionic lead, $\mathrm{Pb}(\mathrm{II})$, lead oxides and hydroxides, and lead metal oxyanion complexes. The most stable forms of $\mathrm{Pb}$ are $\mathrm{Pb}$ (II) and leadhydroxy complexes. Lead(II) is the most reactive and commonly available form, compounding mononuclear and polynuclear oxides and hydroxides. Lead sulfide $(\mathrm{PbS})$ is the most stable solid form that forms when increased concentrations of sulfide are present under reducing condition. Also Lead forms several basic salts, such as $\mathrm{Pb}(\mathrm{OH})_{2} \cdot 2 \mathrm{PbCO}_{3}$, which was once the most widely used white paint pigment and the source of considerable chronic lead poisoning to children who ate peeling white paint (Raskin and Ensley, 2000). 
In addition to the inorganic compounds of lead, there are a number of organolead compounds such as tetraethyl lead. The toxicities and environmental effects of organolead compounds are particularly noteworthy because of the former widespread use and distribution of tetraethyllead as a gasoline additive. Although more than 1000 organo lead compounds have been synthesized, those of commercial and toxicological importance are largely limited to the alkyl (methyl and ethyl) lead compounds and their salts (e.g., dimethyldiethyllead, trimethyllead chloride, and diethyllead dichloride). Under anaerobic conditions Lead undergoes methylation in the environment to form several organic derivatives. A volatile tetramethyl lead (organo lead) can be formed in sediments due to microbial alkylation.

\subsubsection{Geochemical Mobility of Lead (Pb)}

It is naturally occurring and usually found as a mineral combined with sulphur or oxygen in the form of $\mathrm{PbS}, \mathrm{PbSO}_{4}$, or $\mathrm{PbCO}_{3}$, respectively. It ranges from 10 to $30 \mathrm{mg} \mathrm{kg}^{-1}$ in the earth's crust (USDHHS, 1999). Typical average $\mathrm{Pb}$ concentration for surface soils worldwide is $32 \mathrm{mg} \mathrm{kg}^{-1}$ and varies from 10 to $67 \mathrm{mg} \mathrm{kg}^{-1}$ (Kabata-Pendias, and Pendias, 2001).

In general, plants do not absorb or accumulate lead. However, in soils conditions high in lead, it is possible for some amount of lead to be taken up by plants. Previous studies have shown that lead does not accumulate in the fruit crops (Kabata-Pendias, and Pendias, 2001; Rosen, 2002) (eg., corn, tomatoes, beans, strawberries, and apples) and fruiting parts of vegetable. But higher concentrations are more likely to be found in the surface of root crops (e.g. carrots) and in leafy vegetables (e.g. lettuce). Since plants do not take up and accumulate large quantities of soil lead, the safe soil-lead levels for plants will be much higher. Generally, it has been considered safe with total soil lead levels less than $300 \mathrm{ppm}$. As the soil level rises above this level, the health risk of lead through the food chain increases, but most of the risks are from lead contaminated soil or dust deposits rather than from uptake of lead by the plant (Rosen, 2002).

\subsection{Health Effects of Arsenic (As), Cadmium (Cd) and Lead (Pb)}

Arsenic, Cadmium, and Lead are not an essential element and are described as chronic toxin. They can enter the human body through two major routes, ingestion and inhalation (Gastrointestinal Absorption). Another possible route of human contact is dermal absorption. The effects of all routes are same. They have no known essential function in the human body and are very biopersistant once absorb by an organism, remains residents for many years. They are a particularly harmful and dangerous chemical, as they accumulate in individual organisms and in entire food chains which may lead to poisoning or even death. Acute poisoning of $\mathrm{Pb}$ is relatively rare and confined to occupational setting. The effects $\mathrm{Cd}$ and $\mathrm{Pb}$ on human health have been more extensively studied and reviewed than those of As and other trace metals. 


\subsubsection{Arsenic (As)}

As the number of body system affected with As, it is difficult to diagnose signs of chronic toxicity of arsenic. A range of non-specific symptoms are reported such as abdominal pain, vomiting, diarrhea, weight loss and sore throat on the onset after chronic exposure to arsenic. In addition, symmetrical hyperkeratosis of palms and soles, as well as exfoliative dermatitis and melanosis are reported as major indicators of chronic arsenic exposure, which may take years to develop.

There is evidence that chronic arsenic ingestion may cause perivascular and neurological effects. Long-term ingestion of arsenic contaminated drinking water may effect to peripheral vascular diseases and to peripheral nervous system (IARC, 2004). Symptoms may include anaemia, leucopenia, paralysis, tingling of the skin of extremities, foot and wrist drop, tremors, severe pain and ataxia (IPCS, 1992). An increased incidence of cardiac arrhythmias, myocardial injury and cerebrovascular disease has been associated with chronic exposure to inorganic arsenic. There is evidence for increase in the incidence of diabetes mellitus and hepatic and renal injury as a result of chronic arsenic exposure (see Table 02). Non-specific gastrointestinal effects such as diarrhoea and vomiting have been seen under chronic effects (IARC, 2004; IPCS, 1992).

Table 02: Summary of key effects observed in humans after chronic arsenic exposure (Pritchard, 2007)

\begin{tabular}{|l|l|}
\hline System or Organ & \multicolumn{1}{c|}{ Effect } \\
\hline Respiratory Tract & Inflammation and tracheobronchitis \\
\hline Dermal & Hyperkeratosis and changes to pigmentation (melanosis) \\
\hline Vascular & Peripheral vascular disease (“Blackfoot disease”), myocardial injury \\
\hline Haematological & Bone marrow depression (resulting in leucopenia and anaemia) \\
\hline Neurological & Peripheral neuropathy, encephalopathy \\
\hline Endocrine & Diabetes mellitus \\
\hline Liver & Hepatomegaly, cirrhosis, altered haem metabolism \\
\hline Kidneys & Proximal tubule degeneration, papillary and cortical nephrosis \\
\hline Gastrointestinal & Diarrhea, vomiting \\
\hline
\end{tabular}

\subsubsection{Cadmium (Cd)}

As reported in toxicological facts, $\mathrm{Cd}$ is a chronic toxin. Chronic exposure to cadmium $(\mathrm{Cd})$ leads to renal failure characterised by proteinuria due to renal tubular dysfunction as a result of $\mathrm{Cd}$ adversely affecting enzymes responsible for reabsorption of proteins in kidney tubules. This has been evidenced by an increase in urinary beta-2-microglobulin. Such proteinuria occur following 
25-134 $\mathrm{gm}^{-3}$ cadmium inhalation or ingestion for more than 10 years (IPCS, 1992). The inhalation of fumes and vapours causes kidney damage, bronchitis, gastric and intestinal disorders. Cadmium inhalation also causes cancer, disorder of heart, liver and brain, renal dysfunction, anaemia, hypertension and bone marrow disorder (Friberg et al., 1974).

The cadmium accumulation in the kidney affects renal vitamin D metabolism, which subsequently disturbs calcium and phosphorous balance by the excretion of calcium and phophorous into urine that may lead to osteomalacia, osteoporosis (Soderland et al., 2010) and spontaneous fractures. This, as well as the increased excretion of calcium may result in bone disease (Chandrajith et al., 2010).

The most spectacular disease of cadmium poisoning as result of dietary intake of cadmium by people in the Jintsu River Valley, Toyama, Japan, is known as itai itai disease. The symptoms are weak and brittle bones resulting painful bone disease (osteomalacia) combined with kidney malfunction. Cadmium poisoning was attributed to rice contaminated from $\mathrm{Pb}, \mathrm{Zn}$, and $\mathrm{Cd}$ due to mining activities. The major threat to human health is chronic accumulation of $\mathrm{Cd}$ in the kidneys leading to renal dysfunction.

\subsubsection{Lead $(\mathrm{Pb})$}

Lead is a chronic toxin and therefore, blood lead $(\mathrm{PbB})$ concentration is taken as a measure of the chronic exposure to assess the health effects (Lead Toxicological Overview, 2012). Table 03 summarizes the effects of $\mathrm{PbB}$ at different levels.

In case of renal failure, it was reported that chronic exposure to lead can lead to nephrotoxicity characterised by renal effects, such as glomerular sclerosis, interstitial fibrosis and proximal tubular nephropathy (IPCS, 1992) which have been commonly observed among the patients with CKDu in Sri Lanka (Chandrajith et al., 2010). The most critical effects of lead toxicity can be seen in children exposed during fetal and/or postnatal development (IPCS, 1992). Excessive exposure to Lead can cause serious damage to the gastrointestinal tract, brain, red blood cells, central nervous system, and kidneys (EFSA, 2010; Baldwin, and Marshall, 1999).

Unfortunately there is no scientific data available on $\mathrm{PbB}$ concentrations related $\mathrm{CKDu}$ in Sri Lanka except $\mathrm{Pb}$ high concentrations in fertilizers determined by Chandrajith et al., 2009. Elevated Cadmium levels in irrigation and drinking water has been reported from the North Central Province (NCP) of Sri Lanka, where chronic renal failure among residents is common. This is a result of intensive use of cadmium contaminated fertilizers and other agricultural chemicals over a very long period of time. Cadmium is one of the most toxic heavy metals that could find its way into reservoir water and sediments. In 
NCP of Sri Lanka, natural vegetation and grassland associated with the main reservoirs used for irrigation and drinking purposes are contaminated with cadmium and lead (0.03-0.06 mg/1 of $\mathrm{Cd}$ and $0.01-0.03 \mathrm{mg} / \mathrm{lof} \mathrm{Pb}$ ). Many farmers and residents of NCP traditionally depend on reservoir water for washing, bathing and drinking in addition to irrigation.

The trace metals in the environment are considered as a major geoenvironmental factor that could contribute to the etiology of renal damage. There is also a suggestion that, at least to some extent, the fluoride content of drinking water contributes to the CKDu. Based on observations of past researches, there is strong evidence that $\mathrm{CKDu}$ has a profound relationship to drinking water consumption.

Table. 03 Symptoms and Effects of Blood Lead (PbB) Concentration (Lead Toxicological Overview, 2012)

\begin{tabular}{|c|c|c|}
\hline $\begin{array}{l}\text { Blood Lead (PbB) } \\
\text { Conc. }(\mu \mathrm{g} \mathrm{dL}-1)\end{array}$ & Symptoms & Effects \\
\hline $\mathrm{PbB}<10$ & Risk of spontaneous abortion (JECFA, 2011) & Reproductive effects \\
\hline $10<\mathrm{PbB}<20$ & $\begin{array}{l}\text { Risk of spontaneous abortion, prematured } \\
\text { delivery, low birth weight (JECFA, 2011) and } \\
\text { reduced GFR (IPCS, 1995; ATSDR, 2007) }\end{array}$ & $\begin{array}{l}\text { Reproductive effects } \\
\text { and renal failure }\end{array}$ \\
\hline $20<\mathrm{PbB}<30$ & Reduced fertility & Reproductive effects \\
\hline $30<\mathrm{PbB}<50$ & $\begin{array}{l}\text { Proteinuria, enzymuria, peripheral nerve } \\
\text { dysfunction, low semen volume and } \\
\text { sperm counts, increased abnormal sperm, } \\
\text { morphology and decreased sperm motility } \\
\text { in males (IPCS, 1995; ATSDR, 2007; EFSA, } \\
\text { 2010; RAIS, 1994; Baldwin, and Marshall, } \\
\text { 1999; WHO, 2000). }\end{array}$ & $\begin{array}{l}\text { Renal failure, } \\
\text { neurotoxicity, and } \\
\text { reproductive effects } \\
\text { (Male) }\end{array}$ \\
\hline $40<\mathrm{PbB}<50$ & $\begin{array}{l}\text { All above, reduced hemoglobin production, } \\
\text { headache, dizziness, fatigue, lethargy, } \\
\text { irritability, malaise, slurred, convulsions, } \\
\text { sleep disturbances, muscle \& joints pains, } \\
\text { paraesthesia, tremors, ataxia, paralysis, } \\
\text { vomiting, nausea, anorexia, and constipation } \\
\text { (Campbell , 2006; ATSDR, 2007; RAIS, } \\
\text { 1994; Baldwin, and Marshall, 1999) }\end{array}$ & $\begin{array}{l}\text { Cardiovascular } \\
\text { \& Renal toxicity, } \\
\text { Hematological } \\
\text { effect, neurotoxicity, } \\
\text { gastrointestinal } \\
\text { toxicity }\end{array}$ \\
\hline $50<\mathrm{PbB}<60$ & $\begin{array}{l}\text { Severe deficit in renal function (IPCS, 1995; } \\
\text { ATSDR, 2007) }\end{array}$ & Renal damage \\
\hline $60<\mathrm{PbB}$ & Expect mortality (WHO, 2000) & \\
\hline
\end{tabular}




\section{Discussion}

\subsection{Farmers, Fertilizer, Agrochemicals and Chronic Heavy Metal Exposure}

Farmers generally belong to low income group and are not bothered about environmental benefits or hazards. They are interested in maximizing their crop yields and profits. Addition of fertilizers to soils and application of agrochemicals to crops has become common practice in agriculture. The main purposes are the improvement of the nutrient supply in soil by adding fertilizers, and protect crop from diseases by applying pesticides. Long-term practice of these two activities may results in chemical degradation of the soil as the foreign contaminants are accumulated over time.

The fertilizers and the pesticides used in agriculture usually contain significant amounts of heavy metals such as $\mathrm{Cu}, \mathrm{As}, \mathrm{Co}, \mathrm{Cr}, \mathrm{Mo}, \mathrm{Sr}, \mathrm{Ti}, \mathrm{V}, \mathrm{Mn}, \mathrm{Fe}, \mathrm{Ni}$, $\mathrm{Zn}, \mathrm{Cd}, \mathrm{Pb}, \mathrm{Hg}, \mathrm{Ba}$ and $\mathrm{Sc}$. Long-term irrigation of land and application of inorganic fertilizers, animal manure and pesticides in agriculture tends to increase the levels of concentrations of heavy metals in the environment that are toxic to human and plants. It is worth to mention here that environmental concentrations of such metals can fluctuate in considerable amounts with the changes in the meteorological conditions and the nature of agricultural activities. This is the reason for the controversial determinations observed for Cd concentrations in five reservoirs by Chandrajith et al., 2010. In the context of environmental conditions and nature of anthropological activities are concerned, effects and $\mathrm{Cd}$ and other metals on CKDu in NPC in Sri Lanka cannot be simply ruled out.

\subsection{Exposure to Heavy Metals}

As discussed above, routes of exposure to heavy metals by farmers can be through ingestion, inhalation and transdermal. Farmers first expose to fertilizers and agrochemicals when handling and applying to soils and crops. They never use and personal protective equipments (PPE) eg. gloves, masks, when they handle fertilizers and agrochemical. Heavy metals can enter the body through inhalation and transdermal routes. Especially, when they work in the paddy fields, legs are in contact with heavy metal rich mud and water (Dermal absorption). But dermal absorption of inorganic heavy metals is generally quite low compared to other two major routes.

Another major route of exposure is ingestion and inhalation. Human exposure to inorganic heavy metals occurs primarily through ingestion of food and drinking water. However, the health effects are the same regardless of the route of exposure. 
Absorption of Cd, Pd and other heavy metals GI track depends on their physical and chemical state, and is influenced by physiological status, age, nutritional status and genetic factors. Low levels of calcium, iron, copper, zinc, selenium or phosphate in the diet can increase $\mathrm{Pb}$ absorption. Absorbed $\mathrm{Pb}$ is distributed by blood to bones, teeth and soft tissues, and is deposited in the body, in the form of insoluble lead phosphate, in the skeleton that is rapidly growing and mainly excreted in the urine. The metabolism of inorganic $\mathrm{Pb}$ mainly occurs through reversible lagans reactions. $\mathrm{Pb}$ form complexes with amino acids and non-protein thiols and bind to various proteins.

Unlike $\mathrm{Pb}$, absorbed $\mathrm{Cd}$ binds mainly to red blood cells and high molecular proteins in the blood and accumulate in the kidneys and in the liver $(50-70 \%$ of body burden) because it binds with metallothionein produced (80-90\%) in the kidneys and the liver. $\mathrm{Cd}$ has little or no metabolism though it binds with red blood cells or proteins. In the liver, methllothionein production is sufficient to bind all cadmium accumulated. The metallothionein-bound $\mathrm{Cd}$ is then released from the liver into the blood for clearence by glomerular filtration in the kidney and is taken up by the renal tubules, where the metallothionein is cleaved and cadmium is released. The metallothionein synthesized in the kidney is insufficient to bind all these free cadmium, eventually causing tubular damage or destruction of cell membrane.

\section{Acknowledgement}

Financial support given by the National Research Council of Sri Lanka under the NRC Grant Number 12-125 is highly appreciated.

\section{References}

Adriano, D.C. (2003). Trace Elements in Terrestrial Environments, Biogeochemistry, Bioavailability and Risks of Metals, Springer, New York, USA, 2nd edition.

Agency for Toxic Substances and Disease Registry (ATSDR) (2007). Toxicological Profile for Lead, US Department of Health and Human Services: Atlanta, US.

Amore, J.J.D., Al-Abed, S.R., Scheckel, K.G. and Ryan, J.A. (2005). Methods for speciation of metals in soils: A review, Journal of Environmental Quality, v 34, pp.1707-1745.

Aturaliya, T.N.C., Abeysekera, D.T.D.J. and Amerasinghe, P.H. (2003). Chronic renal failure, towards understanding the current trend, Kandy Society of Medicine Annual Sessions. 
Aturaliya, T.N.C., Abeysekera, D.T.D.J., Amerasinghe, P.H., Kumarasiri P.V .and Bandara, P. (2006). Towards understanding of Chronic Kidney disease of North Central Province, In Proceedings of annual scientific sessions of Sri Lanka Medical Association.

Background -Chronic Kidney Diseases, www.emedicine.com

Bandara,J.M., Senevirathna, D.M., Dasanayake, D.M., Bandara, J.M., Abeysekara, D.T. and Rajapaksha. K.H. (2008). Chronic renal failure among farm families in cascade irrigation systems in Sri Lanka associated with elevated dietary cadmium levels in rice and freshwater fish (Tilapia). Environ Geochem Health , v 30(5):465-478.

Baldwin, D.R. and Marshall, W.J. (1999). Heavy metal poisoning and its laboratory investigation, Annals of Clinical Biochemistry, 36, pp. 267300.

Basta, N.T., Ryan, J.A. and Chaney, R.L. (2005). Trace element chemistry in residual-treated soil: key concepts and metal bioavailability, Journal of Environmental Quality, v (34), pp.49-63.

Bodek,I., Lyman, W.J., Reehl, W.F. and Rosenblatt, D.H. (1988). In Environmental Inorganic Chemistry: Properties, Processes and Estimation Methods, Pergamon Press, Elmsford, New York, USA.

Campbell, P.G.C. (2006). Cadmium-A priority pollutant, Environmental Chemistry, 3, pp.387-388.

Carlos, M.O. Herrera, R., Almaguer, M., Brizuela, E.G., Hernández, C.E., Bayarre, H., Amaya, J.C., Calero, D.J., Orellana, P., Rosa, M., Colindres, R.N., Velázquez, M.E., Núñez, S.G., Contreras V.M. and Castro, B.E. (2009). CKD and associated risk Factors in the Bajo Lempa Region of El Salvador: Nefrolempa Study, MEDICC Review, v 13, pp.14-22.

Chaney,R.L. and Oliver, D.P. (1996). Sources, potential adverse effects and remediation of agricultural soil contaminants, Contaminants and the Soil Environments in the Australia- Pacific Region, R. Naidu, Ed., Dordrecht, The Netherlands, pp.323-359.

Chandrajith, R., Seneviratna, S., Wickramaarachchi, K., Attanayaka,T., Aturaliya, T.N.C. and Disanayake, C.B. (2009). Natural Radio nuclides and trace elements in the rice field soils in relation to fertilizer application: study of a chronic kidney disease area in Sri Lanka, Geoenvironment.

Chandrajith, R., Nanayakkara, S., Itai, K., Aturaliya, T.N.C., Dissanayake, C.B., Abeysekera, T. , Harada, K., Watanabe, T. and Koizumi, A. (2010). Chronic kidney diseases of uncertain etiology (CKDue) in Sri Lanka: Geographic Distribution and Environmental Implications, Environ Geochem Health, DOI 10.1007/s10653-010-9339-1. 
EFSA (European Food Safety Authority) Panel on Contaminants in the Food Chain (CONTAM) (2010). Scientific Opinion on Lead in Food, EFSA Journal, v 8, p. 1570.

Friberg, L.M., Piscaor, G.F.and Nordberg, T. (1974). Cadmium in the environmental, 2nd ed., CRC Press, Cleveland.

Foncin,J.F.,and El Hachimi, K.H. (1986). Neurofibrial degeneration in Alzheimer's disease: A discussion with a contribution to aluminium pathology in man. Senile dementias early detection 191-201.

Fonseka,S., Jayasumana, C., Jayalath,K., Amarasinghe, M., Senanayake, K., Wijewardhane, C., Samarasinghe, D., Dahanayake, K., Mahamithawa, P. and Paranagama, P. (2012). Arsenic and hardness in ground water from chronic kidney disease of unknown etiology (CKDu) prevalent areas and non-CKDu prevalent areas in Sri Lanka, Symposium Proceeding, International Symposium on water quality and human health:Challenges Ahead, 22-23 March, University of Peradeniya, Sri Lanka.

Herath,K.R.P.K., Illeperuma, O.A., Dharmagunawardhane, H.A. and Haller K.J.(2005). Environmental health risk for the chronic renal failure in Sri Lanka paper presented at the 31st congress on Science and Technology,October, in Suranaree University of Technology, Thailand.

International Agency for Research on Cancer (IARC) (2004). Summaries and Evaluations. Arsenic in Drinking Water (Group 1). 84. Lyon.

International Programme on Chemical Safety (IPCS) (1992). Cadmium, Environmental Health Criteria 134, World Health Organization, Geneva.

International Programme on Chemical Safety (IPCS) (1995). Inorganic lead, Environmental Health Criteria 165, World Health Organisation: Geneva.

Jayasekara, J.M.K.B., Dissananyake ,D.M., Ratnayake, P., Wickramasinghe, W. and Radella, Y.A. (2011). Effect of concentrated water from reservoirs of high prevalence area for CKD of unknown origin in Sri Lanka on mice ; http://www.prn.usm.my/apamten Jointly organized by APAMT and the National Poison Centre of Malaysia, 1.

Jayasekara, J.M.K.B., Dissananyake ,D.M., Ratnayake, P., Wickramasinghe, W. and Radella, Y.A. (2012). Effect of concentrated water from reservoirs of high-prevalence area for CKD of unknown origin in Sri Lanka on Mice. J. of Medical Toxicology, v 8, pp.192-237.

Jayasumana, M.A.C.S., Paranagama,P., Amarasinghe,M., Wijekon, D.V.K. and Fonseka, S.I. (2011). Presence of Arsenic in pesticides used in Sri Lanka, Symposium of Water professionals' Day, University of Peradeniya, October 01, Peradeniya, Sri Lanka. 
Jayasumana, M.A.C.S. (2012). Histopathological features of Sri Lankan Agricultural nephropathy. First international workshop on Mesoamerican Endemic Nephropathy,November 28-30, San Jose, Costa Rica.

Jayasumana, M.A.C.S., Paranagama, P.A., Amarasinghe, M.D., Wijewardane, K.M.R.C., Dahanayake, K.S., Fonseka, S.I., Rajakaruna, K.D.L.M.P., Mahamithawa, A.M.P. Samarasinghe, U.D. and Senanayake, V.K. (2013). Possible link of chronic arsenic toxicity with Chronic Kidney Disease of Unknown etiology in Sri Lanka, Journal of National Sciences Research, V 3(1):pp.64-73

Joint FAO/WHO Expert Committee on Food Additives (JECFA) (2011). WHO Food Additives Series: 64, Safety Evaulation of Certain Food Additives and Contaminants, Prepared by the Seventy-third meeting of the Joint FAO/WHO Expert Committee on Food Additives (JECFA).

Jones, L.H.P. and Jarvis, S.C. (1981). The fate of heavy metals, Chemistry of Soil Processes, D.J. Green \& M. H. B. Hayes (Eds)., New York, NY, USA, 593.

Kaasalainen, M. and Yli-Halla, M. (2003). Use of sequential extraction to assess metal partitioning in soils, Environmental Pollution, v 126, pp.225-233.

Kabata-Pendias, A. and Pendias, H. (2001). Trace Metals in Soils and Plants, CRC Press, Boca Raton, Fla, USA, 2nd edition.

Kirpichtchikova, T.A., Manceau, A., Spadini, L., Panfili, F., Marcus M.A. and Jacquet, T. (2006). Speciation and solubility of heavy metals in contaminated soil using X-ray microfluorescence, EXAFS spectroscopy, chemical extraction, and thermodynamic modeling, Geochimica et Cosmochimica Acta, 70, pp.2163-2190.

Kuo, S., Heilman, P.E. and Baker, A.S. (1983). Distribution and forms of copper, zinc, cadmium, iron, and manganese in soils near a copper smelter, Soil Science, v 135, pp.101-109.

Lead Toxicological Overview (2012). CRCE HQ, HPA, Version 3.

Maslin, P. and Maier, R.M. (2000). Rhamnolipid-enhanced mineralization of phenanthrene in organic-metal co-contaminated soils, Bioremediation Journal, v 4, pp.295-308.

McLaughlin, M.J., Hamon, R.E., McLaren, R.G., Speir, T.W. and Rogers, S.J. (2000). Review: A bioavailability-based rationale for controlling metal and metalloid contamination of agricultural land in Australia and New Zealand, Australian Journal of Soil Research, v 38, pp.1037-1086. 
Prasad, G.V.R., and Rossi, N.F. (1995). Arsenic intoxication associated with tubule interstitial nephritis. American Journal of Kidney Diseases , V 26(2):373-376.

Perera, A.P.G.R.L., Gonawala, J.M.L. and Wijekoon, D. (2008). Groundwater quality in Anuradhapura District with special reference to fluoride, Groundwater in Sri Lanka, National Academy of Science, pp.48-64.

Pierzynski, G.M., Sims, J.T. and Vance, G.F. (2000). Soils and Environmental Quality, CRC Press, London,UK, 2nd edition.

Pritchard, J.D. (2007). Arsenic Toxicological Overview, CRCE HQ, Health Protection Agency, UK, Version 2.

Raven, P.H., Berg, L.R. and Johnson, G.B. (1998). Environment, Saunders College Publishing, New York, NY, USA, 2nd edition.

Raskin, I. and Ensley, B.D. (2000). Phytoremediation of Toxic Metals, Using Plants to Clean Up the Environment, JohnWiley \& Sons, New York, USA.

Risk Assessment Information System (RAIS) (1994). Toxicity profile for lead, Chemical Hazard Evaluation and Communication Group, Biomedical and Environmental Information Analysis Section, Health and Safety Research Division.

Rosen, C.J. (2002). Lead in the home garden and urban soil environment, Communication and Educational Technology Services, University of Minnesota Extension.

Scragg, A. (2006). Environmental Biotechnology, Oxford University Press, Oxford, UK, 2nd edition.

Shiowatana, J., McLaren, R.G., Chanmekha, N. and Samphao, A. (2001). Fractionation of arsenic in soil by a continuous flow sequential extraction method, Journal of Environmental Quality, v 30, pp.1940-1949.

Soderland, P. Lovekar, S., Weiner, D.E., Brooks, D.R. and Kaufman, J.S. (2010). Chronic Kidney Disease Associated With Environmental Toxins and Exposures, Adv Chronic Kidney Diseases., 17, pp.254-264.

Sumner, M.E. (2000). Beneficial use of effluents, wastes, and biosolids, Communications in Soil Science and Plant Analysis, v 31, pp.1701-1715.

United States Renal Data System (USRDS), (2004) annual report, American Journal of Kidney Diseases, v 45 (Suppl. 1).

USDHHS (1999). Toxicological profile for lead, United States Department of Health and Human Services, Atlanta, Ga, USA. 
Wanigasuriya, K., Peiris-John, R., Wickremasinghe, R. and Hittarage, A. (2008). Chronic renal failure in North Central Province of Sri Lanka: An environmentally induced disease. Transactions of the Royal Society of Tropical Medicine and Hygiene, v 101, pp. 1013-1017.

Wanigasuriya, K.P., Peiris-John R.J., and Wickremasinghe, R. (2011). Chronic kidney disease of unknown aetiology in Sri Lanka: is cadmium a likely cause?, BMC Nephrology, v 12, pp.32-38.

Wedeen, R.R.P. and Qiant,L. (1991). Chromium-Induced Kidney Disease, Environmental Health Perspectives, 92 , pp.71-74.

Weggler,K., McLaughlin, M.J. and Graham, R.D. (2004). Effect of Chloride in Soil Solution on the Plant Availability of Biosolid-Borne Cadmium, Journal of Environmental Quality, v 33, pp.496-504.

World Health Organisation (WHO) (2000). Safety evaluation of certain food additives and contaminants WHO Food additives series No 44, WHO: Geneva. 